\title{
Frequency of Insulin Resistance in People with Thyroid Dysfunction
}

\author{
Shaza Abdalla Elwali ${ }^{1 *}$ and Sulaf || Abdelaziz² \\ ${ }^{1}$ Department of Clinical Skills, Faculty of Medicine, Sudan International University, Khartoum, \\ Sudan \\ ${ }^{2}$ Department of Internal Medicine, Faculty of Medicine, University of Khartoum, Khartoum, Sudan \\ ORCID: \\ Shaza Abdalla Elwali: https://orcid.org/0000-0002-1152-776X
}

Corresponding Author: Shaza Abdalla Elwali; email: shaza092009@hotmail.com

Received 21 September 2021 Accepted 03 December 2021 Published 31 December 2021

Production and Hosting by Knowledge E

(c) Shaza Abdalla Elwali and Sulaf I Abdelaziz. This article is distributed under the terms of the Creative Commons

Attribution License, which permits unrestricted use and redistribution provided that the original author and source are credited.

Editor-in-Chief:

Prof. Mohammad A. M. Ibnouf

\section{Abstract}

Background: Thyroid dysfunction is an endocrine disorder with a recognized association with type 2 diabetes mellitus. Thyroid hormones have a remarkable effect on glucose metabolism and can cause insulin resistance (IR). This study was aimed at assessing the relationship between IR and thyroid dysfunction.

Methods: This case-control study was conducted at the endocrinology outpatient clinics of Ibrahim Malik Hospital and Omdurman Military Hospital in Khartoum State, Sudan between May 2018 and January 2019. Fasting blood glucose (FBG), fasting insulin level, and thyroid function test (TFT) were measured for each candidate and IR was estimated using the HOMA-IR equation.

Results: Thirty-one patients with thyroid dysfunction and fifty-seven control participants were enrolled. The highest mean FBG was found among cases $(105.3 \pm 15.7 \mathrm{mg} / \mathrm{dl})$ compared to the controls $(97 \pm 12.1 \mathrm{mg} / \mathrm{dl})$, but the difference was not statistically significant $(P$-value $=0.598)$. The mean fasting insulin level was $9.22 \pm 4 \mathrm{lU} / \mathrm{ml}$ in the cases and $9.4 \pm 4.2 \mathrm{IU} / \mathrm{ml}$ in controls, without a significant difference ( $P$-value $=$ 0.681). The highest HOMA-IR score was found among cases $(2.4 \pm 1.2)$. It was 2.4 \pm 1.3 in hyperthyroidism, $2.3 \pm 1.1$ in hypothyroidism, and $2.4 \pm 1.2$ in controls, and the difference was insignificant $(P$-value $=0.859)$. IR was higher in the cases $(58.1 \%)$ compared to the controls (52.6\%) but again not statistically significant ( $P$-value $=0.396)$. Among cases, IR was encountered in $61.9 \%$ and $50 \%$ of hyperthyroid and hypothyroid patients, respectively.

Conclusion: Patients with thyroid dysfunction have some level of IR that was not statistically significant when compared with controls.

Keywords: thyroid dysfunction, insulin resistance, type 2 diabetes mellitus 


\section{Introduction}

Thyroid disorders are the second most common endocrine disorder after diabetes mellitus. The global epidemiology of thyroid disorders varies from one zone to another depending on iodine sufficiency and deficiency in the area. In Sudan, according to a national study conducted in 1997, the overall burden of all types of goiter was $22 \%$, ranging from $5 \%$ in Khartoum to $42 \%$ in Upper Nile states [1]. On the other hand, the study by Perros et al. showed the overall prevalence of thyroid diseases in people with diabetes mellitus was $13.4 \%$. The occurrence of insulin resistance (IR) in patients with thyroid disorders leads to increased morbidity through its role in the existence of the metabolic syndrome [2].

The thyroid hormones thyroxine (T4) and triiodothyronine (T3) have a large effect on glucose metabolism. Maintaining a normal blood glucose level requires a balance between the intake and production, which is organized by hormones that decrease the blood glucose level, such as insulin, and those that increase it, such as thyroid hormone, glucagon, and glucocorticoids [3].

Normally, thyroid hormones stimulate the nuclear transcription of several genes in almost all body cells, leading to higher total cellular metabolic enzymes. Concerning their role in carbohydrate metabolism, in addition to increasing insulin secretion [3], they elevate glucose uptake by cells, increasing gastrointestinal absorption by upregulating glucose transporter 4 (GLUT4), which elaborates glucose transport, and, through the same action, stimulate glycolysis by upregulating phosphoglycerate kinase. Thus, they act synergistically with insulin to improve glucose utilization in the peripheral tissues [4].

In hyperthyroidism (HR), there is high hepatic glucose generation via the aforementioned mechanisms, and elevated fasting postprandial insulin and pro-insulin levels. Moreover, it correlates with IR. In the tissues, it leads to impaired glucose uptake because of insulin insensitivity, which is caused by the secretion of adipokines such as interleukin 6 (IL6) and tumor necrosis factor alpha (TNF alpha) by adipose tissue [5].

In hypothyroidism, numerous in vitro studies were conducted compared to those in humans, and it was found that there is IR in the peripheral tissues caused by deregulated metabolism of leptin [4]. Other features comprise changed blood flow, impaired GLUT4 translocation, reduced glycogen synthesis, and diminished muscle oxidative capacity. In human studies, a decrease in glucose extraction and blood flow in the muscles and adipose tissue of hypothyroid patients was noticed, causing IR [5]. Other aspects of those with subclinical hypothyroidism are impaired lipid regulation and the occurrence of the metabolic syndrome [4]. 
IR is characterized by insufficient tissue response to the action of insulin, causing high insulin secretion which leads to metabolic abnormalities such as cardiovascular disease, type 2 diabetes mellitus, polycystic ovary syndrome, nonalcoholic fatty liver disease, and others [6].

This study investigates the relationship between IR and thyroid disorders compared to healthy individuals.

\section{Materials and Methods}

This case-control study was conducted at the endocrinology outpatient clinics of Omdurman Military Hospital and Ibrahim Malik Hospital (Khartoum, Sudan) between May 2018 and January 2019.

Thirty-one patients with thyroid dysfunction and fifty-seven control participants were randomly enrolled in the study. All patients with a history of thyroidectomy, diabetes mellitus, chronic kidney disease, multiple comorbidities, and pregnant women were excluded.

Moreover, $6 \mathrm{ml}$ of venous blood was drawn from all candidates for testing insulin, glucose levels, and thyroid hormones. The blood samples were stored at $-20^{\circ} \mathrm{C}$ until all samples were collected and were then tested at the same time.

The reference values were as follows: thyroid-stimulating hormone (TSH): 0.4-7.8 $\mathrm{mU} / \mathrm{l}$, T3: 0.8-3.0 nmol/l, T4: 50-150 nmol/l, fasting blood glucose (FBG) $<100 \mathrm{mg} / \mathrm{dl}$, and insulin level: $1.1-32.0 \mathrm{IU} / \mathrm{ml}$.

HOMA-IR stands for Homeostatic Model Assessment of IR. This is an equation that helps calculate the presence and extent of IR in an individual. It reveals the dynamics between the baseline FBG and the amount of insulin produced in response. Low HOMAIR means good insulin sensitivity. A small amount of insulin is sufficient to maintain glucose homeostasis, while a higher HOMA-IR denotes more IR.

The healthy IR range is $0.5-1.4 ;<1.0$ indicates optimal insulin sensitivity; $>1.9$ indicates early IR; and $>2.9$ indicates significant IR.

HOMA-IR equation $=($ Fasting glucose $[\mathrm{mg} / \mathrm{dL}] \times$ fasting insulin $[\mu \mathrm{U} / \mathrm{mL}] / 405)$.

All subjects were given verbal and written information concerning the study and, after entering the study, signed a written consent form regarding all information received. The study protocol was approved by the Ethics Committee of the Sudan Medical Specialization Board (SMSB), the Director of the Omdurman Military Hospital and Ibrahim Malik Hospital. 


\subsection{Statistical analysis}

Data were analyzed using the Statistical Package for Social Sciences (SPSS v.21.0). The analyzed data are presented in tables designed by Microsoft Excel 2010. The ANOVA test was used for continuous variables and the Chi-Square test for categorical variables. Also, Pearson's correlation was used between HOMA-IR score and thyroid profile among the case group. The $P$-value was considered as significant at the level of 0.05 .

\section{Results}

This study enrolled 31 thyroid disease patients ( 21 with HR and 10 hypothyroidism) as a case group and 57 normal individuals as a control group. Table 1 presents the demographic characteristics of the participants.

The thyroid function test (TFT) profile showed that TSH was significantly higher in controls than in hypothyroidism and HR patients (4.6 mU/I [1.7-7.2] vs $2.1 \mathrm{mU} / \mathrm{I}$ [0.6-14.4] vs $0.6 \mathrm{mU} / \mathrm{l}[0.005-15.4]$; $P$-value $=0.001)$, T3 was higher among HR patients than in hypothyroidism and control group, it was $4.3 \mathrm{nmol} / \mathrm{l}(0.38-102.7)$ vs $1.5 \mathrm{nmol} / \mathrm{l}(0.46-$ 16.9) vs $1 \mathrm{nmol} / \mathrm{l}(0.8-2.0)$, respectively; $P$-value $=0.001$. Similarly, T4 was significantly higher among HR patients compared to hypothyroidism and controls $101 \mathrm{nmol} / \mathrm{l}$ (14-338) vs $79 \mathrm{nmol} / \mathrm{l}(3.9-116)$ vs $93 \mathrm{nmol} / \mathrm{l}(67-134)$, respectively; $P$-value $=0.001$. The highest mean of FBG was found among HR patients $(108.8 \pm 16.5 \mathrm{mg} / \mathrm{dl})$ followed by controls $(97 \pm 12.1 \mathrm{mg} / \mathrm{dl})$ and hypothyroidism $(91.9 \pm 28.7 \mathrm{mg} / \mathrm{dl})$, but the difference was not statistically significant $(P$-value $=0.598)$. The mean fasting insulin level was $10.1 \pm 3.3$ $\mathrm{IU} / \mathrm{ml}$ in hypothyroidism, $9.4 \pm 4.2 \mathrm{IU} / \mathrm{ml}$ in controls, and $8.8 \pm 4.3 \mathrm{IU} / \mathrm{ml}$ in $\mathrm{HR}$, without a statistically significant difference $(P$-value $=0.681)$. The highest HOMA-IR score was found in HR $(2.4 \pm 1.3)$ followed by hypothyroidism $(2.3 \pm 1.1)$ and controls $(2.2 \pm 1.1)$, and the difference was not significant $(P$-value $=0.859)($ Table 2$)$.

Table 3 illustrates that patients in the case group (58.1\%) showed more IR than those in the control group (38.6\%), however, the difference was not statistically significant $(P$-value $=0.396)$.

Table 4 reveals that IR occurred in $61.9 \%$ of HR patients and in $50 \%$ of hypothyroidism patients without a statistically significant difference $(P$-value $=0.403)$.

By using Pearson's correlation, the HOMA-IR score exhibited a weak, insignificant negative correlation with TSH levels $(r=-0.175 ; P$-value $=0.345)$ and T4 levels $(r=-$ $0.224 ; P$-value $=0.216)$, and a weak positive correlation with T3 levels $(r=0.092 ; P$-value $=0.623)($ Table 5$)$. 


\section{Discussion}

The aim of this study was to assess the relation between IR and thyroid dysfunction, to find out if there is a link between hypo/HR and fasting insulin levels and IR, and to compare the presence of IR in people with thyroid dysfunction and healthy people without thyroid disorder.

The study did not show a significant difference in both insulin levels ( $P$-value $=0.681$ ) and HOMA-IR scores $(P$-value $=0.859)$, as well as IR $(P$-value $=0.396)$, and this could be due to the small sample size and the patients were using their anti-thyroid drugs or thyroxine, which may have affected the results.

Despite it being insignificant, FBG was higher in HR patients than in controls and hypothyroidism patients $\left(108.8 \pm 16.5 \mathrm{mg} / \mathrm{dl}\right.$ vs $97 \pm 12.1 \mathrm{mg} / \mathrm{dl}$ vs $91.9 \pm 28.7 \mathrm{mg} / \mathrm{dl} ; P_{-}$ value $=0.598$ ). This is supported by Ohguni et al., who cited that there was no statistically significant difference in fasting plasma glucose among thyroid disease patients and controls [7]. However, on the other hand, Maratou et al. reported HR and subclinical hyperthyroidism (SHR) had higher glucose levels compared to the euthyroid group $(P<$ 0.05) [8].

Insignificantly, fasting insulin is greater in hypothyroid patients $(10.1 \pm 3.3 \mathrm{lU} / \mathrm{ml})$ followed by controls $(9.4 \pm 4.2 \mathrm{IU} / \mathrm{ml})$ and $\mathrm{HR}(8.8 \pm 4.3 \mathrm{IU} / \mathrm{ml})$. The first part is supported by Purohit et al., as they found insulin levels were greater in the hypothyroid group followed by the hyperthyroid and euthyroid groups [9]. This is also supported by other studies done on subclinical hypothyroidism [10,11], and on hypothyroidism and subclinical hypothyroidism versus euthyroid [12]. In contrast, Kunal et al. (2012) reported insulin levels were raised in HR more than in hypothyroidism and euthyroid state. In our study, insulin levels in hyperthyroid patients were lower than in controls, which could be due to the effect of medications.

The study demonstrated that HOMA-IR scores were higher in HR $(2.4 \pm 1.3)$ than in hypothyroidism $(2.3 \pm 1.1)$ and in controls $(2.2 \pm 1.1)$. In addition, IR was encountered in $61.9 \%$ and $50 \%$ of hyperthyroid and hypothyroid patients, respectively. This relation is supported by previous statistically significant studies which found HOMA values were significantly higher in the hyperthyroid and hypothyroid groups as compared to the EU group [13], and other two studies done on subclinical hypothyroidism/subclinical and overt hypothyroidism $[14,15]$. However, another study reported the opposite of the above mentioned, citing that HOMA-IR is greater in hypothyroid (17.29 \pm 15.61$)$ and lower in hyperthyroid $(1.72 \pm 2.46)$ compared to euthyroid (3.33 \pm 0.78$)$ [9]. 
The main limitation of this study is the small sample size, and the current use of medications affects thyroid functions as well as IR parameters.

\section{Conclusion}

IR affects both hypo and HR due to high insulin secretion and impaired tissue sensitivity to it.

\section{Acknowledgements}

The authors would like to thank the patients and staff at Ibrahim Malik Hospital and Omdurman Military Hospital for their assistance in obtaining the data used in this study.

\section{Ethical Considerations}

Ethical clearance was obtained from the Council of Internal Medicine, Sudan Medical Specialization Board (SMSB). All enrolled patients signed a written consent form before they

joined the study groups.

\section{Competing Interests}

The authors declare that they have no competing interests to disclose.

\section{Availability of Data and Material}

All data is available upon request.

\section{Funding}

The authors declare that no funds or grants were involved in supporting this work. 
TABLE 1: The characteristics of the study group.

\begin{tabular}{l|l|l|l}
\hline Age (yr) & Case (N = 31) & Control (N = 57) & P-value \\
\hline$<30$ & $14(45.2 \%)$ & $33(57.9 \%)$ & 0.503 \\
\hline $30-50$ & $15(48.4 \%)$ & $23(40.4 \%)$ & \\
\hline $51-70$ & $2(6.5 . \%)$ & $1(1.8 \%)$ & \\
\hline Gender & $29(93.5 \%)$ & $55(96.5 \%)$ & 0.442 \\
\hline $\begin{array}{l}\text { Female } \\
\text { Male }\end{array}$ & $2(6.5 \%)$ & $2(3.5 \%)$ & \\
\hline BMI (kg/m $\left.{ }^{2}\right)$ & $0(0 \%)$ & $10(17.5 \%)$ & 0.070 \\
\hline $\begin{array}{l}\text { Underweight } \\
\text { Normal }\end{array}$ & $21(67.7 \%)$ & $27(47.4 \%)$ & \\
\hline Overweight & $5(16.1 \%)$ & $11(19.3 \%)$ & \\
\hline $\begin{array}{l}\text { Obese } \\
\text { Thyroid disorder }\end{array}$ & $5(16.1 \%)$ & $9(15.8 \%)$ & \\
\hline Hyperthyroidism & $21(67.7 \%)$ & - & - \\
\hline Hypothyroidism & $10(32.3 \%)$ & & \\
\hline
\end{tabular}

BMI: Body mass index.

TABLE 2: The laboratory investigations of study group.

\begin{tabular}{|c|c|c|c|c|}
\hline & $\begin{array}{l}\text { Hyperthyroidism } \\
(\mathrm{N}=21)\end{array}$ & $\begin{array}{l}\text { Hypothyroidism } \\
(\mathrm{N}=10)\end{array}$ & Control ( $N=57)$ & P-value \\
\hline $\begin{array}{l}\text { TSH (mU/I); Median (max- } \\
\text { min) }\end{array}$ & $0.6(0.005-15.4)$ & $2.1(0.6-14.4)$ & $4.6(1.7-7.2)$ & 0.001 \\
\hline $\begin{array}{l}\text { T3 (nmol/l; Median (max- } \\
\text { min) }\end{array}$ & $4.3(0.38-102.7)$ & $1.5(0.46-16.9)$ & $1(0.8-2.0)$ & 0.001 \\
\hline $\begin{array}{l}\text { T4 (nmol/l); Median (max- } \\
\text { min) }\end{array}$ & $101(14-338)$ & 79 (3.9-116) & $93(67-134)$ & 0.001 \\
\hline FBG $(\mathrm{mg} / \mathrm{dl}) ;$ Mean \pm SD & $108.8 \pm 16.5$ & $91.9 \pm 28.7$ & $97 \pm 12.1$ & 0.598 \\
\hline $\begin{array}{l}\text { Fasting insulin }(\mathrm{IU} / \mathrm{ml}) ; \\
\text { Mean } \pm \mathrm{SD}\end{array}$ & $8.8 \pm 4.3$ & $10.1 \pm 3.3$ & $9.4 \pm 4.2$ & 0.681 \\
\hline $\begin{array}{l}\text { HOMA-IR score; Mean } \pm \\
\text { SD }\end{array}$ & $2.4 \pm 1.3$ & $2.3 \pm 1.1$ & $2.2 \pm 1.1$ & 0.859 \\
\hline
\end{tabular}

TSH: Thyroid stimulating hormone; T3: Triiodothyronine; T4: Thyroxine; FBG: Fasting blood glucose; IR: Insulin resistance.

TABLE 3: The distribution of insulin resistance among the study group.

\begin{tabular}{l|l|l|l|} 
& Case $\mathbf{( N = 3 1 )}$ & $\begin{array}{l}\text { Control } \\
\mathbf{5 7})\end{array}$ & $\mathbf{( N =}=$ P-value \\
$\begin{array}{l}\text { Insulin } \\
\text { resistance }\end{array}$ & $18(58.1 \%)$ & $30(52.6 \%)$ & 0.396 \\
\hline Yes & $13(41.9 \%)$ & $27(47.7 \%)$ & \\
\hline No & &
\end{tabular}


TABLE 4: The insulin resistance among hypothyroidism and hyperthyroidism patients.

\begin{tabular}{|c|c|c|c|}
\hline & $\begin{array}{l}\text { Hypothyroidism ( } N= \\
\text { 10) }\end{array}$ & $\begin{array}{l}\text { Hyperthyroidism }(\mathrm{N}= \\
\text { 21) }\end{array}$ & P-value \\
\hline \multicolumn{4}{|c|}{$\begin{array}{l}\text { Insulin } \\
\text { resistance }\end{array}$} \\
\hline Yes & 5 (50\%) & 13 (61.9\%) & 0.403 \\
\hline No & 5 (50\%) & 8 (38.1\%) & \\
\hline
\end{tabular}

TABLE 5: The Pearson's correlation between HOMA-IR score and thyroid profile among case group.

\begin{tabular}{l|l|l} 
& Correlation coefficient $(r)$ & P-value \\
\hline HOM-IR *TSH & -0.175 & 0.345 \\
\hline HOM-IR *T4 & -0.23 & 0.216 \\
\hline HOM-IR *T3 & 0.092 & 0.623 \\
\hline
\end{tabular}

\section{References}

[1] Medani, A. M. M., Elnour, A. A., and Saeed, A. M. (2011). Endemic goitre in the Sudan despite long-standing programmes for the control of iodine deficiency disorders. Bulletin of the World Health Organization, vol. 89, no. 2, pp.121-126.

[2] Perros, P., McCrimmon, R. J., Shaw, G., et al. (1995). Frequency of thyroid dysfunction in diabetic patients: value of annual screening. Diabetic Medicine, vol. 12, no. 7, pp. 622-627.

[3] Hall, J. E. (2016). Guyton and Hall Textbook of Medical Physiology (13 ${ }^{\text {th }}$ ed.). Available at: https://dokumen.pub/guyton-and-hall-textbook-of-medical-physiology13nbsped.html (Accessed 2021 April 28).

[4] Wang, C. (2013). The relationship between type 2 diabetes mellitus and related thyroid diseases. Journal of Diabetes Research, vol. 2013, p. 390534.

[5] Brenta, G. (2011). Why can insulin resistance be a natural consequence of thyroid dysfunction? Journal of Thyroid Research, vol. 2011, article 152850.

[6] Einhorn, D., Reaven, G. M., Cobin, R. H., et al. (2003). American College of Endocrinology position statement on the insulin resistance syndrome. Endocrine Practice: Official Journal of the American College of Endocrinology and the American Association of Clinical Endocrinologists, vol. 9, no. 3, pp. 237-252.

[7] Ohguni, S., Notsu, K., and Kato, Y. (1995). Correlation of plasma free thyroxine levels with insulin sensitivity and metabolic clearance rate of insulin in patients with hyperthyroid Graves' disease. Internal Medicine, vol. 34, no. 5, pp. 339-341.

[8] Maratou, E., Hadjidakis, D. J., Peppa, M., et al. (2010). Studies of insulin resistance in patients with clinical and subclinical hyperthyroidism. European Journal of Endocrinology, vol. 163, no. 4, pp. 625-630. 
[9] Purohit, P. (2012). Estimation of serum insulin, Homeostasis model assessment-insulin resistance and C-peptide can help identify possible cardiovascular disease risk in thyroid disorder patients. Indian Journal of Endocrinology and Metabolism, vol. 16, no. 1, pp. S97-S103.

[10] Al Sayed, A., Al Ali, N., Bo Abbas, Y., et al. (2006). Subclinical hypothyroidism is associated with early insulin resistance in Kuwaiti women. Endocrine Journal, vol. 53, no. 5, pp. 653-657.

[11] Tuzcu, A., Bahceci, M., Gokalp, D., et al. (2005). Subclinical hypothyroidism may be associated with elevated high-sensitive c-reactive protein (low grade inflammation) and fasting hyperinsulinemia. Endocrine Journal, vol. 52, no. 1, pp. 89-94.

[12] Maratou, E., Hadjidakis, D. J., Kollias, A., et al. (2009). Studies of insulin resistance in patients with clinical and subclinical hypothyroidism. European Journal of Endocrinology, vol. 160, no. 5, pp. 785-790.

[13] Kapadia, K. B., Bhatt, P. A., and Shah, J. S. (2012). Association between altered thyroid state and insulin resistance. Journal of Pharmacology \& Pharmacotherapeutics, vol. 3, no. 2, pp. 156-160.

[14] Vyakaranam, S., Vanaparthy, S., Nori, S., et al. (2014). Study of insulin resistance in subclinical hypothyroidism. International Journal of Health Sciences and Research, vol. 4, no. 9, pp. 147-153.

[15] Singh, B. M., Goswami, B., and Mallika, V. (2010). Association between insulin resistance and hypothyroidism in females attending a tertiary care hospital. Indian Journal of Clinical Biochemistry, vol. 25, no. 2, pp. 141-145. 